This item was submitted to Loughborough's Research Repository by the author.

Items in Figshare are protected by copyright, with all rights reserved, unless otherwise indicated.

\title{
$2.3 \%$ efficiency gains for silicon solar modules using a durable broadband anti-reflection coating
}

PLEASE CITE THE PUBLISHED VERSION

https://doi.org/10.1109/pvsc45281.2020.9300862

PUBLISHER

IEEE

VERSION

AM (Accepted Manuscript)

\section{PUBLISHER STATEMENT}

Personal use of this material is permitted. Permission from IEEE must be obtained for all other uses, in any current or future media, including reprinting/republishing this material for advertising or promotional purposes, creating new collective works, for resale or redistribution to servers or lists, or reuse of any copyrighted component of this work in other works.

\section{LICENCE}

All Rights Reserved

\section{REPOSITORY RECORD}

Law, Adam, Lewis Wright, Alex Smith, Patrick Isherwood, and Michael Walls. 2021. "2.3\% Efficiency Gains for Silicon Solar Modules Using a Durable Broadband Anti-reflection Coating”. Loughborough University. https://hdl.handle.net/2134/13602986.v1. 


\section{3\% Efficiency Gains for Silicon Solar Modules Using a Durable Broadband Anti-reflection Coating}

\author{
$1^{\text {st }}$ Adam M Law \\ CREST \\ Loughborough University \\ Loughborough, UK \\ A.Law@lboro.ac.uk \\ $5^{\text {th }}$ John M Walls \\ CREST \\ Loughborough University \\ Loughborough, UK \\ J.M.Walls@lboro.ac.uk
}

\author{
$2^{\text {nd }}$ Lewis D Wright \\ CREST \\ Loughborough University \\ Loughborough, UK \\ A.Smith8@lboro.ac.uk
}

\author{
$3^{\text {rd }}$ Alex Smith \\ CREST \\ Loughborough University \\ Loughborough, UK \\ L.Wright2@lboro.ac.uk
}

\author{
$4^{\text {th }}$ Patrick J M Isherwood \\ CREST \\ Loughborough University \\ Loughborough, UK \\ P.J.M.Isherwood@lboro.ac.uk
}

\begin{abstract}
The front surface reflection losses from solar cover glass account for over $4 \%$ of incident light, limiting module efficiency. The application of a multilayer broadband antireflection coating reduces reflection losses over the wavelength range utilised by silicon solar cells. A 6-layer anti-reflection coating comprising $\mathrm{SiO}_{2}$ and $\mathrm{ZrO}_{2}$ has been deposited on glass using high rate pulsed-DC magnetron sputtering. The reflection losses are reduced by $\mathbf{2 . 4 \%}$ absolute compared to uncoated glass. The increased light reaching the solar cell leads to improvements in $I_{s c}$ and spectral response, increasing the efficiency from 17.1 to $17.5 \%$, a relative increase of $2.34 \%$. The coating is environmentally robust. The sputtering process is already used for other high throughput applications by major glass manufacturers.

Index Terms-Anti-reflection (AR) coating, photovoltaics (PV), sputtering
\end{abstract}

\section{INTRODUCTION}

All commercial silicon solar panels incorporate a sheet of cover glass on the outer surface. The glass provides stability and protection for the underlying cells, but also causes an optical loss of $\sim 4 \%$ due to reflection at the glass/air interface.

Single layer anti-reflection (AR) coatings are often used to reduce reflection using materials with a low refractive index. Magnesium flouride $\left(\mathrm{MgF}_{2}\right)$ has been used for research cells [1]. Porous silica $\left(\mathrm{SiO}_{2}\right)$ is currently used on commercial modules for outdoor use [2]. Single layer AR coatings minimise reflection at a single wavelength but can be effective over wide wavelength ranges. However, porous silica has been shown to be vulnerable to degradation in high humidity conditions [3] as well as abrasion testing [4].

Multilayer anti-reflection (MAR) coatings reduce reflection over an extended wavelength range. They are commonly used in precision optics and on ophthalmic lenses [5]. These coatings also exhibit superior durability. The materials used are solid dielectric metal-oxide thin films of materials such as silica and zirconia $\left(\mathrm{ZrO}_{2}\right)$. Previous work has reported on the design, performance and durability of MAR coatings for thin film photovoltaics (PV) [6] [7].
TABLE I

THE MATERIALS USED IN EACH COATING LAYER AND THEIR RESPECTIVE THICKNESSES.

\begin{tabular}{|c|c|c|}
\hline Layer & Material & Thickness (nm) \\
\hline Medium & $\mathrm{Air}$ & \\
\hline 1 & $\mathrm{SiO}_{2}$ & 102 \\
\hline 2 & $\mathrm{ZrO}_{2}$ & 26 \\
\hline 3 & $\mathrm{SiO}_{2}$ & 21 \\
\hline 4 & $\mathrm{ZrO}_{2}$ & 148 \\
\hline 5 & $\mathrm{SiO}_{2}$ & 27 \\
\hline 6 & $\mathrm{ZrO}_{2}$ & 20 \\
\hline Substrate & Glass \\
\hline
\end{tabular}

In this paper we report on the design and performance of a 6-layer MAR coating optimised for the band gap of silicon solar cells. We provide details of our fabrication method using an industrially scalable magnetron sputtering process. The performance of the coating is demonstrated using current-voltage $(\mathrm{I}-\mathrm{V})$ and external quantum efficiency (EQE) measurements.

\section{Coating Design}

The coating designed in this work comprises 6 layers of alternating $\mathrm{SiO}_{2} / \mathrm{ZrO}_{2}$, with the optimum thickness of each layer calculated using an optical modelling program used for the design and optimisation of optical coatings by the transfer matrix method [8]. The coating design and calculated layer thicknesses are presented in Table I. The total thickness of the 6-layer coating is $344 \mathrm{~nm}$.

The weighted average reflection (WAR) is also calculated for the coating. WAR is a weighted reflection measurement accounting for the variation in photon flux at each wavelength in the AM1.5g spectrum. The WAR of the modelled coating used in this work is $1.61 \%$ across a wavelength range of 350$1150 \mathrm{~nm}$. This is a $2.57 \%$ improvement compared with the WAR of $4.18 \%$ for uncoated glass across the same range. 


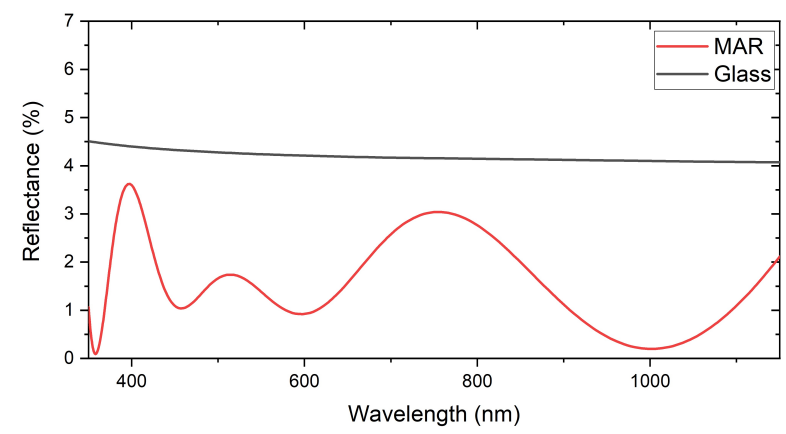

Fig. 1. Modelled reflectance of 6-layer MAR coating compared to uncoated glass (front surface only).

\section{EXPERIMENTAL DETAILS}

\section{A. Coating Deposition}

The MAR coating was deposited onto $5 \mathrm{~cm} \times 5 \mathrm{~cm}$ glass substrates using pulsed-DC magnetron sputtering, with a MyCoat deposition system supplied by Visionease Inc (Ramsey, $\mathrm{MN})$. The process is described in detail in [7]. The flow rates for argon and oxygen gas for the deposition of $\mathrm{SiO}_{2}$ layers were 16 and 10 standard cubic centimetres per minute (SCCM), respectively. The power to the target was set at $1500 \mathrm{~W}$, with a pulse frequency of $150 \mathrm{kHz}$ and a reverse time of $1.5 \mu \mathrm{s}$. The $\mathrm{ZrO}_{2}$ layers were deposited using argon and oxygen flow rates of 20SCCM. The power was set at $1458 \mathrm{~W}$, with a pulse frequency of $150 \mathrm{kHz}$ and reverse time of $2.5 \mu \mathrm{s}$. The targets used were 6-inch diameter circular zirconium and silicon targets.

\section{B. Electrical \& Optical Measurements}

Crystalline silicon solar cells were used to compare the performance of coated and uncoated glass substrates, with I-V measurements taken under standard test conditions (STC) using a Wacom dual source solar simulator. EQE measurements were taken across a wavelength range of 350-1150nm using an in-house system [9]. Reflection measurements were taken across the same range using a Varian Cary5000 UV-VIS-NIR spectrophotometer with integrating sphere attachment.

\section{RESULTS}

The MAR coating reduces front-surface reflectance significantly over the wavelength range utilised by silicon cells (350$1150 \mathrm{~nm}$ ) and the measured reflectance (Fig. 2) is in excellent agreement with the model (Fig. 1). The measured reflectance includes the back-surface reflection from the glass substrate. The WAR is reduced by $2.4 \%$ compared to uncoated glass.

A summary of the electrical data is presented in Table II. Application of the MAR coated cover glass increased the short-circuit current $\left(\mathrm{I}_{s c}\right)$ from $128 \mathrm{~mA}$ to $131 \mathrm{~mA}$ (Fig. 3). The improved $\mathrm{I}_{s c}$ led to an increase in efficiency from $17.1 \%$ to $17.5 \%$. EQE measurements (Fig. 4) show the improvement in spectral response for the MAR coated sample.

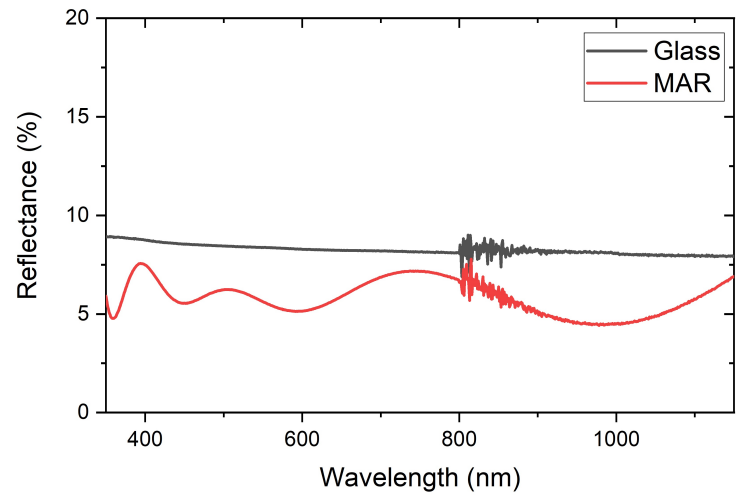

Fig. 2. Measured reflectance of 6-layer MAR coating compared to uncoated glass (both surfaces).

\section{Summary}

The addition of a broadband MAR coating to solar cell cover glass results in a reduction of front surface reflection losses of $2.4 \%$ (absolute) across the wavelength range of 350-

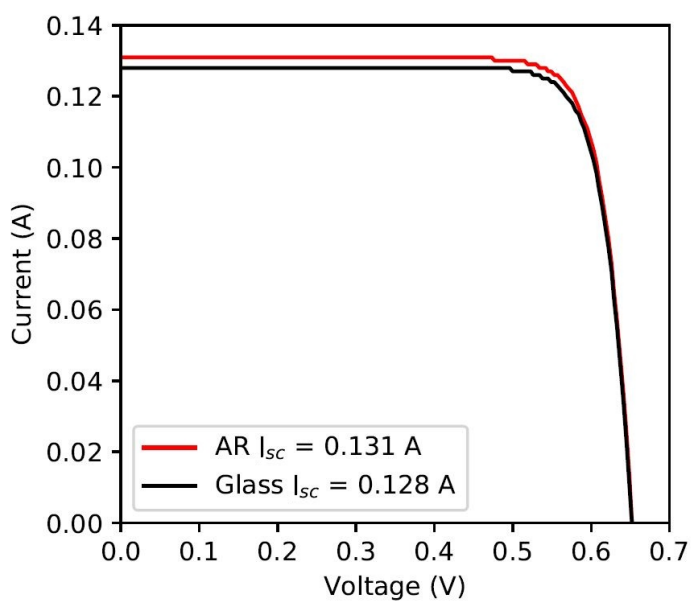

Fig. 3. I-V curves for coated and uncoated glass.

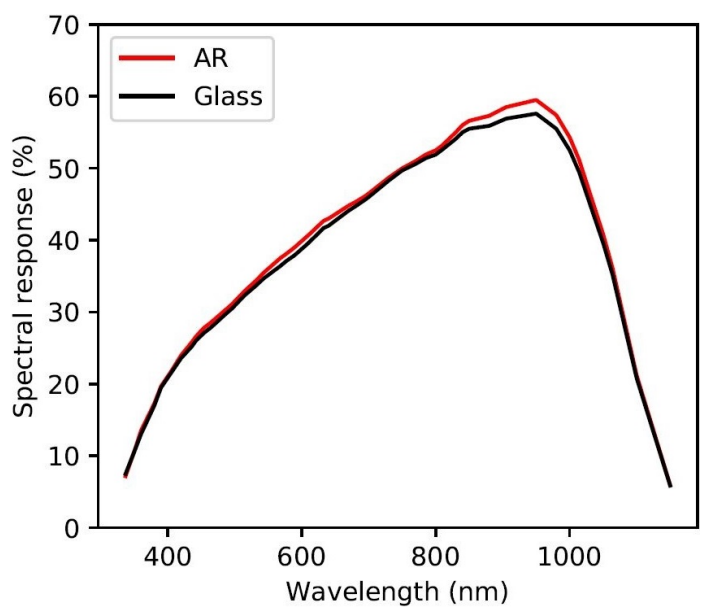

Fig. 4. Spectral response for coated and uncoated cover glass. 
TABLE II

SUMMARY OF ELECTRICAL DATA FOR COATED AND UNCOATED GLASS.

\begin{tabular}{|c|c|c|c|c|}
\hline & $\mathbf{I}_{s c}(\mathbf{A})$ & $\mathbf{V}_{o c}(\mathbf{V})$ & $\mathbf{F F}(\%)$ & $\mathbf{E f f}(\%)$ \\
\hline Uncoated & 0.128 & 0.651 & 81.99 & 17.1 \\
Coated & 0.131 & 0.652 & 82.03 & 17.5 \\
\hline \hline Increase & 2.34 & 0.15 & 0.05 & 2.34 \\
\hline
\end{tabular}

$1150 \mathrm{~nm}$. The increase in light intensity reaching the cell leads to direct improvements in $\mathrm{I}_{s c}$ and spectral response for silicon solar cells, with a relative increase in efficiency of $2.34 \%$. The coating uses inexpensive and abundant materials, as well as being environmentally durable. The coating was deposited using magnetron sputtering, which is already widely used for high throughput applications by major glass manufacturers.

\section{REFERENCES}

[1] Xuanzhi Wu. High-efficiency polycrystalline cdte thin-film solar cells. Solar energy, 77(6):803-814, 2004.

[2] C Ballif, J Dicker, D Borchert, and T Hofmann. Solar glass with industrial porous sio 2 antireflection coating. Solar energy materials and solar cells, 82(3):331-344, 2004

[3] G Womack, K Isbilir, F Lisco, G Durand, A Taylor, and J M Walls. The performance and durability of single-layer sol-gel anti-reflection coatings applied to solar module cover glass. Surface and Coatings Technology, $358: 76-83,2019$.

[4] Klemens Ilse, Charlotte Pfau, Paul-T Miclea, Stephan Krause, and Christian Hagendorf. Quantification of abrasion-induced arc transmission losses from reflection spectroscopy. In 2019 IEEE 46th Photovoltaic Specialists Conference (PVSC), pages 2883-2888. IEEE, 2019.

[5] JM Walls, AG Spencer, and P Southworth. Anti-reflection coating of prescription lenses. Opt. World, 24:12, 1995.

[6] P. M. Kaminski, F. Lisco, and J. M. Walls. Multilayer Broadband Antireflective Coatings for More Efficient Thin Film CdTe Solar Cells. IEEE Journal of Photovoltaics, 4(1):452-456, jan 2014.

[7] G Womack, P Kaminski, A Abbas, K Isbilir, R Gottschalg, and J M Walls. Performance and durability of broadband antireflection coatings for thin film cdte solar cells. Journal of Vacuum Science \& Technology A: Vacuum, Surfaces, and Films, 35:021201, 032017.

[8] Angus Macleod and Christopher Clark. Optical coating design with the Essential Macleod. 2012.

[9] Christopher J. Hibberd, Martin Bliss, H.M. Upadhyaya, and Ralph Gottschalg. Characterisation of a filter-based external quantum efficiency measurement system. In PVSAT. Loughborough University, 2009. 